\title{
Analysis on Communication Value of Phenomenal IP Plays
}

\author{
Shengnan $\mathrm{Yu}$ \\ Heihe University \\ Heihe, China
}

\begin{abstract}
In 2015, the emergence of phenomenal IP plays causes IP upsurge. From the perspective of its communication value, on communication idea, these TV series are precise localization and excellent production following the trend. Media content is simultaneous implementation of humanity essence and spirit of innovation. Channels of communication are integrated communication of multimedia. The communication audience is expansion of audience at all ages and high-end audience. Communication effect is healthy IP ecological construction of sincerity works. This shows the analysis on communication value of phenomenal IP plays is useful reference to produce high quality products that meet the market requirements at home and abroad, set up IP brand and build a complete industrial chain and healthy communication ecology.
\end{abstract}

Keywords—phenomenal IP plays; communication value

\section{INTRODUCTION}

"IP" is the abbreviation of "Intellectual Property". In Chinese, it means "intellectual property". IP plays refer to movie and television plays that the copyright derives from network literature, original literature or games with a large number of fans. In recent years, film and television companies competitively buy this kind of copyright, thus it presents the phenomenon of "IP" fever. In 2015, IP plays develop rapidly and are broadcasted on television. From Silent Separation, the Journey of Flower to Nirvana in Fire and the Legend of Miyue, these plays receive favorable comments in the market as well as public praise. Almost all of them become phenomenal films and television programs. The audience rating is in the front rank of ranking list from beginning to end. When a large number of IP plays enter the market, it also brings a series of realistic problems such as homogenization of contents, emptied resource of good quality, low quality adaptation and high copyright fee. Therefore, in order to make IP plays move further and better and create larger market value, the success of these phenomenal IP plays in aspects such as communication idea, communication content, channels of communication, communication audience and communication effect is beneficial reference.

\section{COMMUNICATION IDEA: PRECISE LOCALIZATION AND EXCELlENT PRODUCTION THAT FOLLOW THE TREND}

In recent years, the homogenization phenomenon in the market of movie and television plays of our country is serious. The original creativity is seriously insufficient. Although the output increases with each passing year, there are few first class works with relatively great influence. Even though the phenomenal TV play of Legend of Zhen Huan that attracts a lot of attention in the preceding years is actually an IP adapted works as well. In addition, the policy of "A Drama Two Stars" executed in January 1, 2015 makes satellite televisions begin a new round of competition to fight for the opportunity to broadcast good plays. Therefore, TV plays must follow the trend with precise localization and excellent production.

Making a comprehensive survey of phenomenal IP plays broadcasted in 2015, firstly, it shows that the selection of play is of vital importance. Nirvana in Fire, the Legend of Miyue and Silent Separation are high quality works checked by audiences from numerous IP works no matter on conception and pattern, story and characters, taste and style. In Nirvana in Fire, the plot with unceasing suspense, vivid and shocked figures and manifestation of carrying forward justice, eulogizing ties of friendship and worshiping morality and justice all hang on to the trend of the times. It has great difficulty in adapting IP works. Some lack logic and some are difficult to carry out visual appearance. Therefore, most of successful IP plays have low degree of adaptation with precise positioning. Secondly, there is a mighty film and television group behind the success. They are familiar with rules to product movie and television plays. The dispose of details such as play, camera shooting, lighting, music, clothing, make up and stage property is appropriate. They also have very high requirements for skills of narration, rhythm controlling and actor's performance. So to speak, the production is marvelous. For example, the IP play Lonely Empty Court to Late Spring hot broadcasted on Zhejiang Satellite TV in 2016, it is adapted from namesake novel of network writer Feiwo Sicun. The picture presentation is romantic and artistic with proper color matching. More important the originator respects the history and produces elaborately on the basis of referring to plenty of historical materials, relevant rules of imperial family, costume of concubines and ancient customs, which lay the foundation for it to become phenomenal IP play.

\section{COMMUNICATION CONTENT: SiMULTANEOUS IMPLEMENTATION OF HUMANITY ESSENCE AND CREATIVE SPIRIT}

The network culture products such as network novel and online games are main sources of phenomenal IP plays. Take network novels as example, the types of topics are extremely 
rich, covering fantasy, monasticism, and traversing, fictional and semi-fictional types as well as urban youth. The contents involve science fiction, exploration, infighting in palace and love. Although writing proficiency of works is different, through years of propagation and accumulation of fans, it is very easy to attract audiences' attention. In terms of communication content, phenomenal IP plays not only provide recreation and aesthetics but also spread values, namely carry forward humanity essence. For example, the Legend of Miyue presents life story and journey of the heart of Miyue, the first female statesman in Chinese history. Different from "infighting in palace" with slight exploration of human nature in Legend of Zhen Huan, it shows more about political strategy and feelings for home and country even the world. Audiences grow and make choice with her when watching it. Similarly, thinking on human nature, fission of tactics, the ruling class dissimilated by politics, family affection lost in power and influence get rich presentation in Nirvana in Fire. Although the historical framework is fictional, it indeed has Chinese traditional cultural values and properly depicts feelings of between people.

In the aspect of creative spirit, it has a definite object in view on the basis of respecting audiences. At present, in order to maximize commercial profit, on contents, IP plays meet the expectation and all aspects of requirements of audiences as far as possible. Phenomenal IP plays are faithful to the original work to adapt. Producers use a variety of means and make an utmost effort to restore aesthetic expectations of fans. Silent Separation is regarded as one of the successful examples of adaptation of IP play. It is loyal to the original work and restores the leading actor "He Yichen" in each reader' mind. It has appealing love and artistic painting style and can be called classic work.

\section{CHANNELS OF COMMUNICATION: INTEGRATED COMMUNICATION OF MULTIMEDIA INTERACTION}

IP plays derive from internet culture, which decides the channels of its communication cannot do without network. However, they are different from the single profit model of traditional movie and television plays that only rely on television station and website to gain profits of the first round of sales. Therefore, television station and internet are not the only channels of communication for IP plays. They use various communication tools to carry out integrated communication. Phenomenal IP plays implement integrated communication through online and offline interaction with the help of internet. Except for arranging meet-and-greet between directors, actors and fans, they try every means to carry out integrated communication on different marketing platforms. For example, the Journey of Flower launches the namesake mobile game when it is broadcasted on TV. Afterwards, it launches network play the Journey of Flower 2015, then stage play and film. The blockbuster at the beginning of 2016 on ANTV, the New Shushan Knight Errant Swordsman Biography, opens up "Shushan mode" of deep "linkage of TV station+ super IP play+ game". The namesake mobile game is on line prior to TV play and rapidly becomes phenomenal mobile game product and reversely helps the broadcast of network and television. The derivative products also include live action movie, CG film, comic book and other peripheral products. The cooperation between the Legend of Miyue and LETV realizes the vertical ecological system promotes all-around marketing. LETV, LETV video, LETV super phone and LETV super TV multi-screen server use overall popularization and deep operation to excavate its value.

\section{COMMUNICATION AUDIENCE: EXPANSION OF AudienCE AT All AGES AND High-END AudiENCE}

In these years, because the creation interest of domestic movie and television plays doesn't appeal to the audiences and foreign plays from South Korea and America are brought in, a large number of young and high-end audiences leave. IP plays adapted from network novel and games and animation exactly attract audiences back.

In the past TV market, after traditional literary works are changed into TV plays and broadcasted, the phenomenon that it drives the hot sell of the original literary works is very common. But IP plays are different. Phenomenal IP has had many audiences before it is developed. They get together because of network and have very high loyalty degree toward works in the process of communication and interaction. Take the Journey of Flower as an example, during the network communication and publication and distribution of printed book, the original work of fresh Guoguo has accumulated plenty of loyal fans, so that it will naturally get the support of fans for the original work after it is adapted into TV play. Therefore, the primary goal of IP plays for positioning of target audience is the fans group of original IP. As main part of network audience, young people are the main audiences.

The phenomenal IP plays in 2015 realize expansion of audience at all ages and high-end audience through online and offline interactive marketing. For example, Nirvana in Fire carries forward positive energy and integrates popular factors among young people. Tactics and true feelings, rivalries and righteous cause, reality and illusion in the play attract many middle-aged people and high-end audiences and earn favorable comments of audiences at all ages.

\section{COMMUNICATION EFFECT: HEALTHY IP ECOLOGICAL CONSTRUCTION OF SINCERITY WORKS}

For the market of movie and television play with reduction of original creativity of play, serious homogenization and stagnant market, IP plays brings new atmosphere for it and add vigor. IP plays that are planned to broadcast in 2016 will go up on the stage successively. At the beginning of the year, the Imperial Doctress has received great attention. There is no lack of phenomenal IP adaptation plays. But with the appearance of problems such as high quality resources are emptied, the contents develop towards the same direction, the theme is limited, the copyright payment rises correspondingly, the high risk increases, low quality adaptation overdraw appeal, it has become the focus that the industry pays attention to about how far IP plays will go.

Since 2015, several successful phenomenal IP plays give us enlightenment. First is the high quality content. No matter ancient costume play Nirvana in Fire and The Legend of 
Miyue or Silent Separation and The Double Life of Veronique, they all come from famous novels on the network and accumulate good reputation and stable fans after years of propagation, belonging to high quality works through analysis and inspection. Second is development and utilization of the whole industry system. The Journey of Flower is an excellent example. It covers all industries such as network novel, cartoon, TV play, mobile games, browser game, 3D movie and internet play, from single transcoding to joint products. IP plays not only refresh the "sense of presence" but also let resources gather rapidly to form strong industry. The last is excellent sincerity works. A TV play can appeal to audiences even become cultural phenomenon in society because the story, characters and plots attract audiences and touch them and make them reflect on it. Nirvana in Fire and The Legend of Miyue depend on solid play writing, exquisite clothing, make up and stage property, delicate composition of pictures as well as careful performance to become phenomenal IP that appeals to audiences. Therefore, in order to keep the popularity of IP plays and make it enter benign sustainable development, it is necessary to create works with sincerity and build healthy IP ecology.

\section{CONCLUSION}

Dramatic development of entertainment industry in contemporary society and new communication phenomenon unceasingly refresh people's cognition and imagination. Transformation, reform and integration are the inevitable channels for sustainable development of film-television industry. IP plays have broad range of topics. It involves different content forms such as network novel, online game and animation. Besides, adaptations of songs, radio plays, dramas and variety shows are also included. IP content has become a bond to connect all sides. Analysis of communication value of phenomenal IP plays is useful reference to produce high quality products that meet the market requirements at home and abroad, set up IP brand and build a complete industrial chain and healthy communication ecology.

\section{REFERENCES}

[1] Wang Shuang. Interpretation of Communication Sciences of "IP" Fever [J], Media Observer, 2015(8).

[2] Gao Wangyu. IP Plays: Burst into Bloom in Fracture [J], the VideoAudio Circle, 2015(11).

[3] Ambrosia, How Long the Fire of IP Plays Can Burn [J], Publisher, 2015(12).

[4] Li Zhengliang. Zhao Shun. Calm Thinking on "IP Fever" in Film and TV Industry [J], Media Observer, 2016 (1).

[5] Bao Er. Can It Truly Set the Prairie Ablaze after IP? [J], TV Guide, 2016(3). 